\title{
Numerical and experimental investigation of the hygrothermal response of timber frame walls with an exterior air barrier
}

\author{
Jelle Langmans ${ }^{\mathrm{a}, *}$, Ralf Klein ${ }^{\mathrm{b}}$, Staf Roels ${ }^{\mathrm{a}}$ \\ ${ }^{a}$ Department of Civil Engineering, Building Physics Section, KU Leuven \\ Kasteelpark Arenberg 40 - bus 02447, BE-3001 Heverlee, Belgium \\ ${ }^{b}$ Sustainable Building Research Group, Departement of Industrial Engineering, Catholic University College Sint-Lieven \\ G. Desmetstraat 1, BE-9000 Ghent, Belgium \\ * Corresponding author. Tel: +3216 321348; fax: + 3216321980 \\ E-mail address: jelle.langmans@bwk.kuleuven.be (J.Langmans)
}

\begin{abstract}
Laboratory tests and numerical simulations to study the hygrothermal consequences of using an exterior air barrier in light weight building envelopes are discussed. Full-scale test walls are placed between a vertical hot and coldbox, operating at controlled temperatures, humidity levels and total air pressures. The test walls are exposed to different boundary conditions during five consecutive measuring stages. Each test wall is provided with 18 thermocouples, 15 relative humidity, 3 heat flux and 1 pressure gauge sensor, covering the most important positions of the wall. In this way the obtained results can be used as detailed validation data for HAMmodels with a strong focus on natural and forced air convection. The main emphasis of the current paper is the evaluation of a numerical model with the current data set. The model used is a modified version of DELPHIN 5 including a quasi-steady state airflow model with the ability to capture natural convection.
\end{abstract}

Keywords: exterior air barrier, HAM, hotbox/coldbox, numerical simulation, timber frame walls, natural convection

\section{Introduction}

Realising airtight dwellings is an essential element in improving buildings overall energy efficiency (Jokisalo et al., 2009) and avoiding at the same time moisture accumulation in building enclosures (Janssens and Hens, 2003; Derome, 2005; Desta, 2011). In cold and moderate cold climates, such as North West Europe, an airtight building envelope is commonly realised by an interior air barrier system. Realising a good airtightness with an interior barrier however, is very labour-intensive for timber frame construction due to many internal joints, intersections and perforations (Kalamees, 2007; Sandberg et al., 2005). From a practical point of view it seems easier, and thus cost effective, to move the airtight layer to the exterior side of the building envelope as show by in-situ measurements of Holøs (2010) and Langmans (2010) and laboratory results of Thor-Oskar et al. (2011). In this way the most critical moisture load related to air transport, being forced air exfiltration (Tenwolde and Rose, 1996) is excluded by the exterior air barrier system. However, an exterior air barrier would allow that the interior vapour retarder is no longer continuously airtight which can lead to an increased moisture load into the 
building envelope as a result of natural convection entering through gaps in this layer. The impact of internal natural convection in building enclosures is extensively studied by Riesner (2003). Riesner studied full-scale test walls in laboratory conditions which were executed with an airtight interior and exterior layer, so internal natural convection was the only air transfer mechanism possible. The outer layers have been executed by Riesner with vapour open materials such as wood fibreboards while a vapour retarding OSB was used at the warm side of the insulation resulting in a relative vapour open wall design (as defined by Thue et al., 1996). The measurements give clear evidence of moisture redistribution as a result of buoyant driven air flow in the insulation. Vapour enters the building enclosure by diffusion and accumulates subsequently in the upper cold side of the wall driven by buoyant air rotation as depicted in Figure 1.

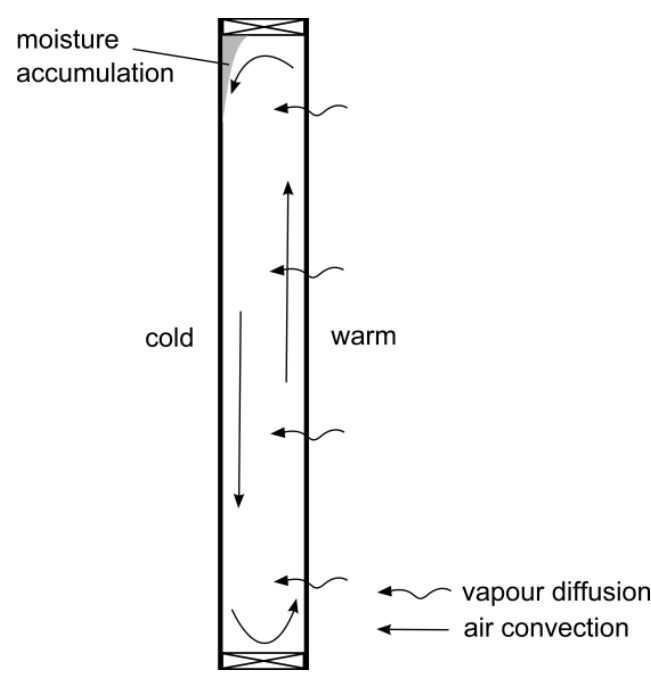

Figure 1. Potential moisture redistribution towards upper cold side as a result of internal natural convection in vapour open wall designs.

Similar results were found by Økland (1998) who tested, in contrast with Riesner (2003), light weight walls with an interior vapour barrier, but with humid initial conditions to simulated built-in moisture. In summary the result of Riesner (2003) and Økland (1998) indicate the potential risk of moisture redistribution as a result of buoyant driven air which can lead to concentrated zones of high moisture levels.

In order to estimate the importance of this effect on the hygrothermal performance of highly insulated light weight walls with an exterior air barrier system, a full-scale laboratory investigation and numerical simulations are performed. The current paper only briefly discusses the test-setup. For a more detailed description on the test walls and measuring results we refer to (Langmans, 2012a). The main emphasis of the present paper, however, is on the confrontation of numerical simulations with the obtained data set from the laboratory tests. 
So far, simulations of combined heat, air and moisture transport in building components have been validated with laboratory measurements by several building physical researchers. However, in most cases this was limited to a qualitative approach as a result of (a) measuring accuracy (b) unknown deviations in the geometry of the component tested and (c) limitations of the model. The first problem, insufficient measuring accuracy, can correspond to various aspects. Most common deficiencies documented in the literature are related to measuring moisture contents, such as calibration difficulties of moisture pin sensors (Økland, 1998) and the impact of air leakages through built-in weights specimens (Li, 2009). In addition, Kalamees and Vinha (2003) mentions the lack of detailed hygrothermal properties (as a function of temperature and moisture content). The second deficiency, unknown geometry, is mostly related to air transfer. Small installation defects can result in increased air transport (Brown 1993) and, consequently, have a large impact on the moisture accumulation as shown by Janssens (1998) with numerical simulations. Thirdly, the omission of dominant transport mechanisms in the simulation model can be the origin of large discrepancies between simulation and measuring results. In this respect Teasdale-St-Hilaire and Derome (2007) mention the lack of forced and natural convection in simulating the drying rate of exterior sheathings with a commercial simulation package.

Notwithstanding the difficulties mentioned in the previous paragraph, hygrothermal modelling of building components is increasingly applied in today's assessment of new building systems and retrofit solutions. However, especially when air transport is involved, the question remains which accuracy level of heat, air and moisture simulations can be expected.

In order to shed light on the above mentioned issues, the present article aims a quantitative comparison between simulations and the experimental results. Therefore, large emphasis was put on creating two dimensional measuring conditions, all hygrothermal material properties were measured in detail and precautions were taken to prevent unintended air leakages in the system.

The simulations in this study are performed with DELPHIN 5 developed at the Technical University of Dresden (Grunewald, 1997; Nicolai, 2007). This HAM-model was already extensively validated in the light of the EUinitiated HAMSTAD-project (Heat, Air and Moisture Standards Development) with one-dimensional benchmark cases (Hagentoft et al., 2004). Furthermore the model was used by Kalamees (2007) to predict the moisture accumulation as a result of forced air convection through the joint of an external wool and attic floor. For the present study, the model was extended to capture natural convection. The experimental and simulation results are compared, and possible explanations for the discrepancies between both are addressed in detail. 


\section{Experimental work}

\subsection{Wall configurations and sensor positioning}

Four highly insulated test walls, each with a test area (h $\mathrm{x} \mathrm{b}$ ) of $2.3 \mathrm{~m} \times 0.5 \mathrm{~m}$, have been tested under laboratory conditions in a hotbox/coldbox setup. All four test walls are insulated with $30 \mathrm{~cm}$ of standard mineral wool to which OSB is applied as interior sheathing. The test walls differ from each other by the physical properties of the applied exterior air barrier; airtightness, moisture buffer capacity, vapour permeability and thermal resistance (Figure 2).

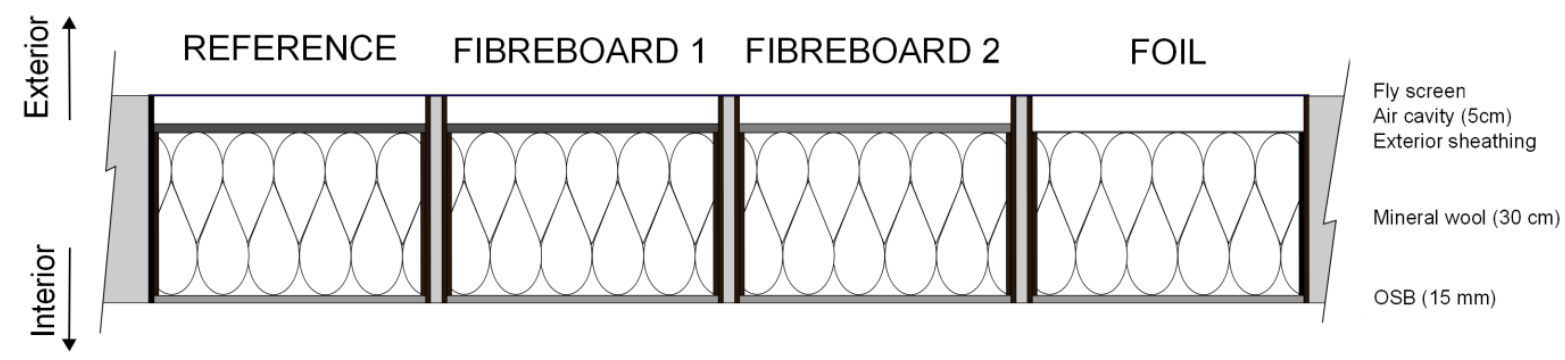

Figure 2. Test wall configurations studied.

Both the exterior sheathing of the first test wall (herein referred to as REFERENCE) and the second test wall (referred to as FIBREBOARD 1) consist of bituminous impregnated soft fibreboard which has a cellulose/bitumen mixed exterior top layer which increases its airtightness. For the third test wall (FIBREBOARD 2) a similar bituminous impregnated soft fibreboard but without top layer is applied. The first three test walls have a hygroscopic exterior sheathing. The fourth wall (FOIL), however, is executed with a spunbonded foil at the outside. The applied foil is extremely airtight but has no water buffer capacity. Hygrothermal properties of the applied materials will be discussed in detail in section 2.4.

In order to generate validation data for numerical HAM-models special care was given to eliminate unintended air leakages and create two-dimensional conditions. During their installation, the test walls were pressurized and with a combination of smoke and infrared inspection the remaining air leakages were detected and carefully caulked. The walls are separated with a polyurethane board $(5 \mathrm{~cm})$ in between two wood fibreboards $(1.8 \mathrm{~cm})$ which are covered with an airtight and watertight paint to prevent any significant heat or mass exchange between the test walls. Furthermore, no top and bottom plate were used in the test walls. As a consequence of these measures the test walls are a simplification of real walls which have wooden studs, top and bottom plates and 
most probably a number of (small) air gaps. However, to generate useful validation data it was necessary to minimise the number of potential uncertainties.

Each test wall is provided with 18 thermocouples placed at three heights: (1) $20 \mathrm{~cm}$ from the bottom, (2) mid height and (3) $20 \mathrm{~cm}$ from the top, at every material interface, in the ventilation cavity and the middle of the insulation layer. Also 15 relative humidity sensors were installed at the same positions except at the interface OSB-mineral wool (warm side). In addition, heat fluxes are measured at this interface at the three heights. For each wall also a pressure gauge was installed at the mid height. Figure 3 gives an overview of the sensors installed within each wall.

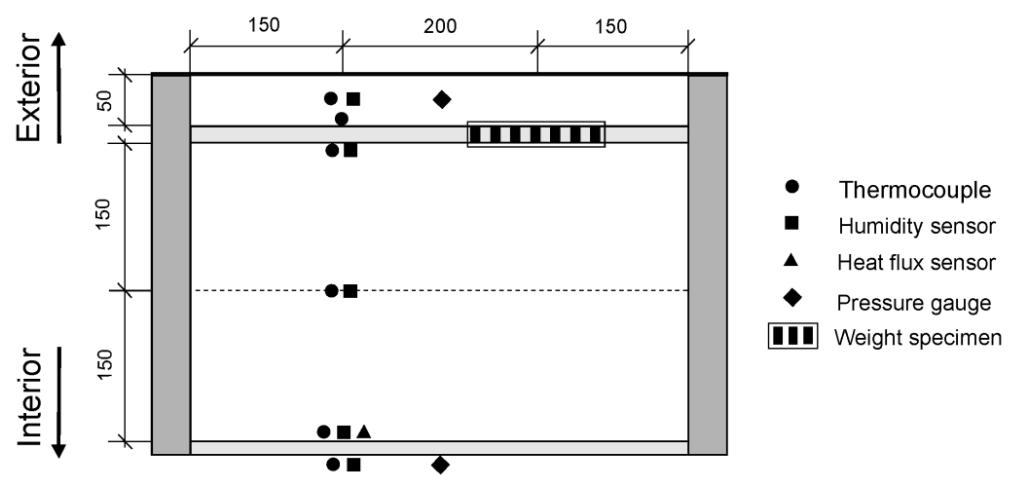

Figure 3. Sensor positioning within each wall section (dimensions in $\mathrm{mm}$ ).

Besides this continuous logging system, the fibreboard exterior air barriers were constructed in such a way that each air barrier contained three removable specimens $(18 \mathrm{~cm}$ by $18 \mathrm{~cm})$. Similar to the sensor positions, these weight specimen were installed on three height: (1) $20 \mathrm{~cm}$ from the bottom, (2) mid height and (3) $20 \mathrm{~cm}$ from the top. They are used to quantify the moisture evolution of the fibreboard by weighing the specimen on a twoweekly basis. Special care was given to the airtightness of the perimeter of each specimen. A special layer was attached on the wood fibreboard, on which the joints could be sealed with airtight tape after every measurement. To check the quality of the sealing method, the airtightness of a board with a specimen was measured in the laboratory. The air permeability of the fibreboard with sealed specimen was quantified beforehand on a $35 \times 35 \mathrm{~cm}^{2}$ specimen and showed to be less than $5 \%$ more than the fibreboard only.

\subsection{Boundary conditions and test sequence}

The experiment, which lasted about four months, was subdivided in five main consecutive measuring steps. In the first four steps the test walls were exposed to typical Belgium winter conditions with increasing rates of natural and forced air convection. During the first step both the interior and exterior sheathing are kept airtight. 
In the second step, gaps are introduced in the interior barrier of all walls except for the REFERENCE section. The gaps correspond to slots of $1 \mathrm{~cm}$ at $20 \mathrm{~cm}$ from the top and bottom and extend the full width of each OSB panel to maintain the two dimensional situation. In step 3 and 4 an increasing overpressure was created in the hotbox.

Finally, in the last step the conditions in the coldbox were adapted to create drying conditions inside the walls. Table 1 summarises the boundary conditions in both the warm and cold chamber in which positive pressure correspond to overpressures in the warm chamber. The first four climate conditions represent an averaged typical winter month in a temperate climate, such as Belgium. The fifth step corresponds to arbitrary drying conditions.

Table 1. Boundary condition in hotbox (HB) and coldbox (CB) during the consecutive measuring steps

\begin{tabular}{ccccccc}
\hline Days & $\begin{array}{c}\mathbf{T}_{\mathbf{H B}} \\
\left({ }^{\circ} \mathbf{C}\right)\end{array}$ & $\begin{array}{c}\mathbf{P}_{\mathbf{v}, \mathbf{H B}} \\
(\mathbf{P a})\end{array}$ & $\begin{array}{c}\mathbf{T}_{\mathbf{C B}} \\
\left({ }^{\circ} \mathbf{C}\right)\end{array}$ & $\begin{array}{c}\mathbf{P}_{\mathbf{v}, \mathbf{C B}} \\
(\mathbf{P a})\end{array}$ & $\begin{array}{c}\mathbf{P}_{\mathbf{a}} \\
(\mathbf{P a})\end{array}$ \\
\hline 1$)$ & 35 & 20.1 & 1181 & 3.0 & 653 & 1.9 \\
$2)$ & 28 & 20.0 & 1178 & 3.2 & 680 & 0.8 \\
$3)$ & 24 & 20.1 & 1243 & 3.2 & 685 & 5.8 \\
$4)$ & 11 & 20.1 & 1249 & 3.2 & 691 & 10.7 \\
$5)$ & 32 & 25.0 & 1688 & 22.6 & 1997 & 1.7 \\
\hline
\end{tabular}

\subsection{Material properties}

This section gives an overview of the hygrothermal properties of the applied materials in the experiment. As mentioned above only the exterior air barrier of the four test walls differs. Three different air barrier materials were carefully selected to compare a maximum number of different phenomena. The parameters investigated are the thermal resistance (FIBREBOARD $1=$ FIBREBOARD $2>$ FOIL), hygroscopic buffer capacity $($ FIBREBOARD 1 = FIBREBOARD $2>$ FOIL), air permeance $($ FIBREBOARD $2>$ FIBREBOARD $1>$ FOIL) and vapour permeance (FIBREBOARD $1<$ FIBREBOARD $2<$ FOIL) of the different exterior sheathing materials.

\subsubsection{Heat transfer properties}

Table 2 gives an overview of the heat transfer properties of the used materials. The heat conductivity of the materials was measured at the laboratory according to ISO 8302:1991. The conductivity was measured as function of the temperature and fitted with the following linear relation:

$$
\lambda=\lambda_{0}+\theta \cdot \lambda_{\theta}
$$

The heat capacity $c_{p}$ was collected either from product sheets or literature (Kumaran, 1996). 


\subsubsection{Air transfer properties}

All the air permeability measurements were performed with the test-setup described in Langmans (2010). The permeability of the mineral wool was measured both perpendicular $\mathrm{K}_{\perp}$ and parallel $\mathrm{K}_{\|}$to the fibres on specimen of $0.2 \times 0.2 \times 0.2 \mathrm{~m}^{3}$. The air permeability levels of the sheathing materials were also measured in the laboratory and are summarized in Table 2. Air transport through a porous medium, such as mineral wool or sheathing materials, can be described by Darcy law, and corresponds to a constant permeability. However, when it comes to air transport through air leakage paths, such as the horizontal slots in the OSB layer, the air resistance depends on the pressure difference. Mostly this is described as a power law function. Figure 4 gives the measured air flow through a $1 \mathrm{~cm}$ slot in a OSB specimen.

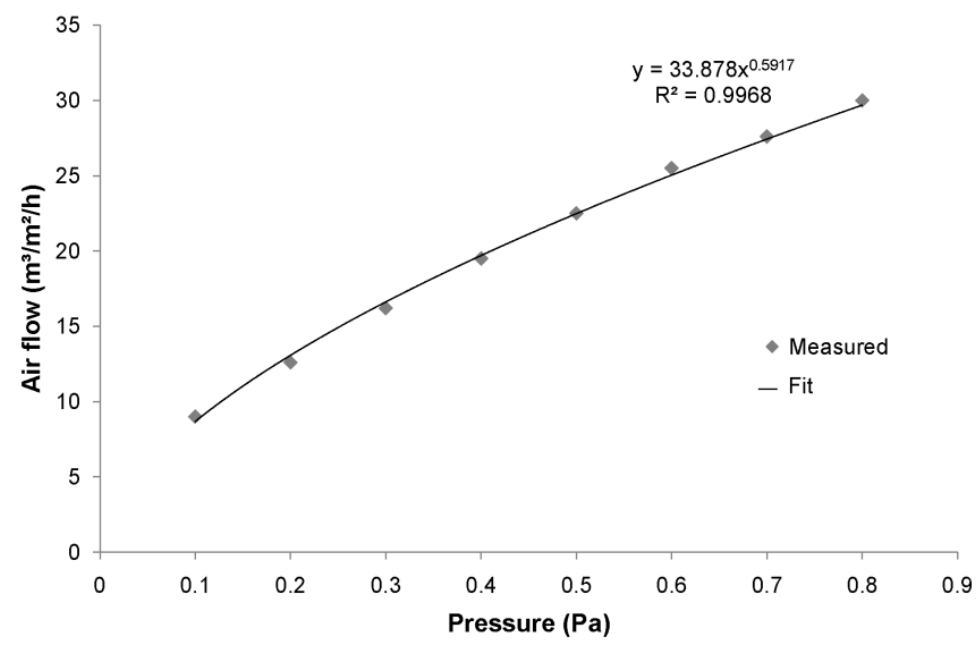

Figure 4. Air leakage through gap of $1 \mathrm{~cm}$ in OSB

\subsubsection{Hygric properties}

The moisture capacity of the building components is measured by determining the hygroscopic sorption curves.

The results, which are fitted with Eq. 2, are shown in Figure 5:left.

$$
u=v\left(1+(m \cdot \ln (\phi))^{n}\right)^{\frac{1-n}{n}}
$$

Also water vapour transmission properties of the applied materials were measured at $23{ }^{\circ} \mathrm{C}$ according to ISO12572:2001 . The results, which are fitted with Eq. 3, are shown in Figure 5:right.

$$
s_{d}=\frac{1}{a+b . e^{c \phi}}
$$

Liquid water transport in the interior sheathing and mineral wool insulation is unlikely to occur. Therefore only the water absorption coefficients of the exterior fibreboard sheathings were measured according to Roels (2004). 
The results reveal that these materials are non-capillary. The moisture increase during the absorption experiment has the same order of magnitude as the hygroscopic loading of the material. Additional contact angle measurements confirmed the hydrophobic behaviour of these materials. In summary, we conclude that Fibreboard 1 and 2 are strongly hygroscopic, moisture buffering and vapour permeable, but non-capillary.

Table 2. Hygrothermal material properties

\begin{tabular}{rccccc}
\hline & Fibreboard 1 & Fibreboard 2 & Foil & OSB & Mineral Wool \\
\hline$d(\mathrm{~mm})$ & 18 & 18 & 0.2 & 15 & 300 \\
$\rho\left(\mathrm{kg} / \mathrm{m}^{3}\right)$ & 285 & 274 & - & 630 & 21.3 \\
$c_{p}(J /(\mathrm{kg} K))$ & 2068 & 2068 & - & 1880 & 840 \\
$\lambda_{0}(W / \mathrm{m} / K)$ & 0.045 & 0.047 & - & 0.1 & 0.031 \\
$\lambda_{\theta}$ & 0.0001 & 0.0001 & - & 0.0002 & 0.0001 \\
$K^{\perp}\left(m^{2}\right)$ & $4.65 \mathrm{E}-14$ & $1.37 \mathrm{E}-12$ & airtight & $8.20 \mathrm{E}-15$ & $1.30 \mathrm{E}-09$ \\
$K^{\|}\left(m^{2}\right)$ & - & - & - & - & $3.80 \mathrm{E}-09$ \\
\hline
\end{tabular}
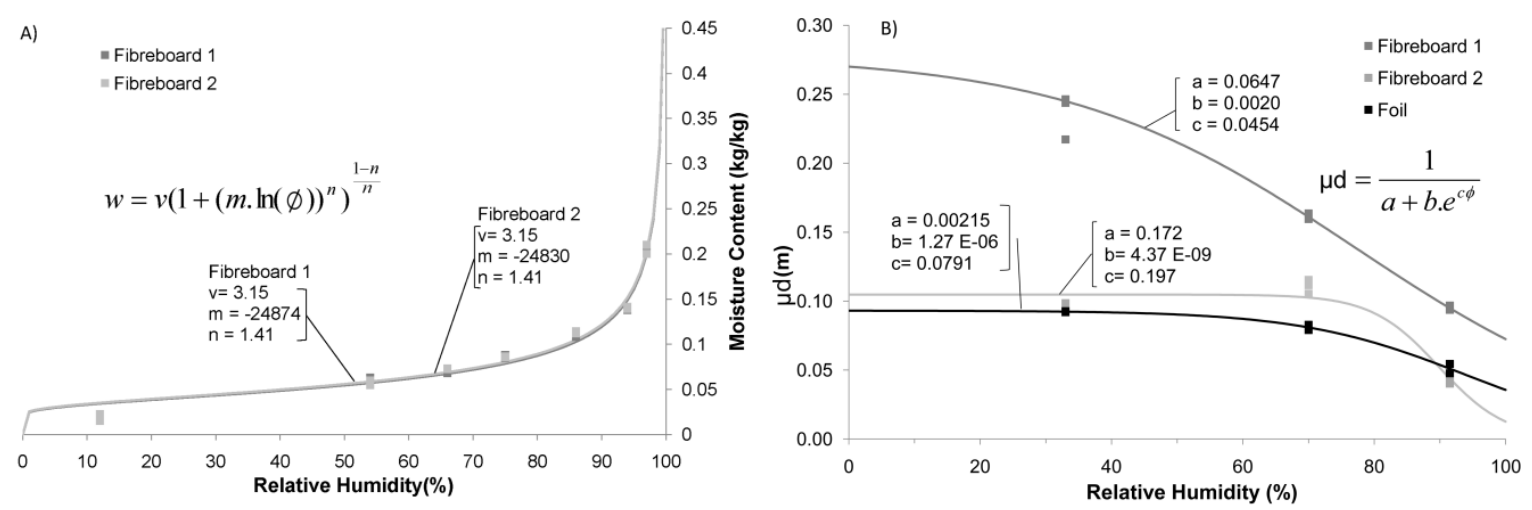

Figure 5. (a) Sorption isotherm and (b) vapour diffusion resistance of the different wind barriers as function of relative humidity.

\section{Numerical simulations}

\subsection{Principle model equations}

The HAM-model used is a modified version of DELPHIN 5 (Grunewald, 1997). This tool describes the combined heat, air and moisture transport in building enclosures. The corresponding conservation equations are briefly repeated from (Nicolai, 2007):

$\frac{\partial u}{\partial t}=-\nabla\left[q_{\text {cond }}+h_{v}\left(j_{\text {diff }}^{v}+j_{\text {conv }}^{v}\right)+h_{w} j^{w}+h_{a} j^{a}\right]+\Sigma \dot{u}$ 
$\frac{\partial \rho^{w+v}}{\partial t}=-\nabla\left[j_{d i f f}^{v}+j_{c o n v}^{v}+j^{w}\right]$

Here, $u$ is an enthalpy density $\left(\mathrm{J} / \mathrm{m}^{3}\right), \rho$ mass density $\left(\mathrm{kg} / \mathrm{m}^{3}\right), q_{\text {cond }}$ the conduction heat flux $\left(\mathrm{W} / \mathrm{m}^{2}\right), j$ a mass flux $\left(\mathrm{kg} / \mathrm{m}^{2} / \mathrm{s}\right)$ and $\dot{u}$ an energy source density $\left(\mathrm{W} / \mathrm{m}^{3}\right)$. The superscripts $w, v$ and $a$ indicate liquid water, water vapour and the dry air components respectively. The subscripts describe the mode of transport through diffusion (diff) or convection (conv) and $h_{w}, h_{v}$ and $h_{a}$ are the specific enthalpies $(\mathrm{J} / \mathrm{kg})$ of the individual components considered. For more details about the heat and moisture transport equations and the numerical solution strategy we refer to (Nicolai, 2007).

For the further discussion also the air transport equations are given here. Air transport in porous media is modelled as Darcy flow:

$j^{a}=-\rho_{a} \frac{k_{a}}{\eta}\left(\nabla p_{a}+\rho_{a} g \cos \alpha\right)$

in which $k_{a}$ correspondents with the air permeability $\left(m^{2}\right), \eta=1.8 \times 10^{-5}$ Pa.s represents the dynamic viscosity, $g$ $=9.81 \mathrm{~m} / \mathrm{s}^{2}$ is the gravity acceleration and $\alpha$ represents the inclination angle.

To improve the numerical stability when taken natural convection into account, the introduction of the Boussinesq approximation in calculating the air mass density appeared to be essential:

$\rho_{a}=\frac{P_{a}}{R \cdot T} \cong \frac{P_{a t m}}{R \cdot T}$

More details on the numerical calculation strategy and the evaluation of the model with analytical and numerical benchmarks from the literature can be found in Langmans (2012b).

\subsection{Boundary conditions and discretisation grid}

For the simulations the calculation domain was discretised in 1484 cells $(28 \times 53)$ using a variable distant grid as shown in Figure 6. The measured temperature, relative humidity and air pressure of the cold and warm boundary at the mid height are applied as boundary conditions for the simulations. The boundary air pressures ascribed to the model are adjusted over the height with the hydrostatic air pressure based on the measured temperature at both sides. The boundary conditions were applied as hourly data to the transient simulations. 


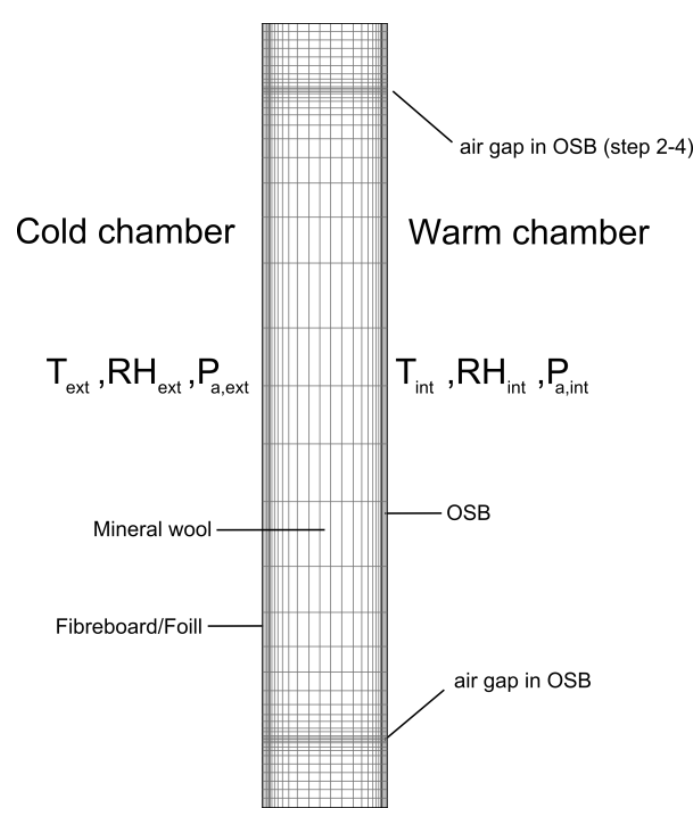

Fig. 6. Variable discretisation grid $(28 \times 53)$ and applied boundary conditions.

\section{Comparison between measurements and simulations}

\subsection{Thermal comparison}

As a first step in comparing the simulations with the measured data the focus lies on the temperature distribution in the test walls. Figure 7 shows the dimensionless temperature profiles of the four walls at the top and bottom row for measuring stage 1,2 and 4 for both the simulations and measurement $\left(\Theta_{\text {in }}=\right.$ temperature in hotbox, $\Theta_{\mathrm{ex}}=$ temperature in coldbox and $\Theta_{i}=$ temperature profile in wall). This corresponds to the situations where (1) the interior OSB sheathing is intact, (2) top and bottom gaps in the interior sheathing are introduced and (3) an overpressure of $11 \mathrm{~Pa}$ is realised in the warm chamber. The simulated temperature profiles are represented in Figure 7 as lines and the measured temperatures with markers. Full lines and markers correspond to the temperatures at the top position and dotted lines and hollow markers to the temperatures at the bottom position. The first measuring step is coloured in blue, the second in red and the fourth step in green.

During the first step the measuring data clearly shows that the temperature distribution bends upwards at the top and downwards at the bottom indicating the existence of natural convection within all four walls. This is confirmed by the simulations, which show an identical profile. However, where the simulated temperature profiles are the same for all four test walls during this step, small differences in the measured temperature profiles exists as will be addressed in section 5 .

During the second measuring step the effect of natural convection on the temperature profile increases as a result of the introduction of the gaps in the interior sheathing. Furthermore, both the simulations and measurements 
show that the temperature profile in FIBREBOARD 2 bends upwards. This means that the exterior sheathing is even so air permeable that as a result of the $1.9 \mathrm{~Pa}$ pressure differential across this wall (introduced by the ventilators in the cold chamber) forced exfiltration already dominates the air flow in this test wall.

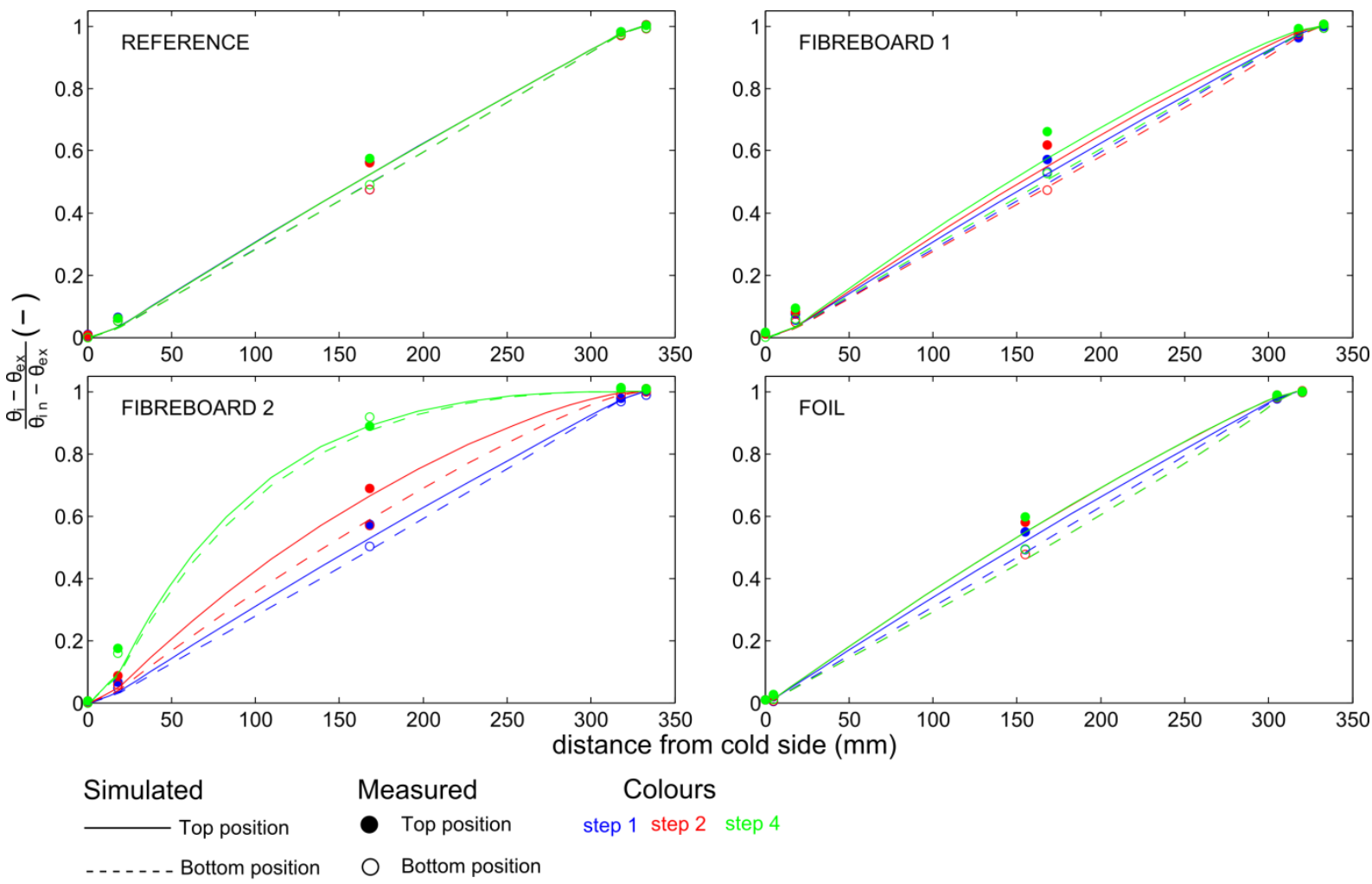

Fig. 7. Simulated dimensionless temperature distribution at top and bottom position versus measured temperatures. (For interpretation of the references to colour in this figure legend, the reader is referred to the web version of this article.)

When finally an overpressure of $11 \mathrm{~Pa}$ is realised in the fourth step this effect becomes much more dominant in FIBREBOARD 2. Also for FIBREBOARD 1 the effect of forced exfiltration is (to a minor degree) observed. For the most airtight wall (FOIL) this remains negligible.

In addition, the data of FIBREBOARD 1 is used to illustrate the order of magnitude of the air convection and its impact on the temperature. Figure 8 compares the simulated temperature and air velocity field with and without the gaps in the interior sheathing (step 1 and step 2). It is clearly visible how the temperature field is affected by providing the gaps. Furthermore, the figure shows how the velocity field is changed by the gaps. Introducing gaps results in on overall increase of the air velocities in the insulation layer. The maximum velocity for the closed situation is $0.12 \mathrm{~mm} / \mathrm{s}$ and is located at the mid height of the wall at the boundaries of the insulation. For the open situation the maximum velocity becomes $15 \mathrm{~mm} / \mathrm{s}$ and is located near the gaps. The velocity at the mid height of the wall at the cold boundary becomes $0.23 \mathrm{~mm} / \mathrm{s}$ for the open situation. 
Step 1

a)

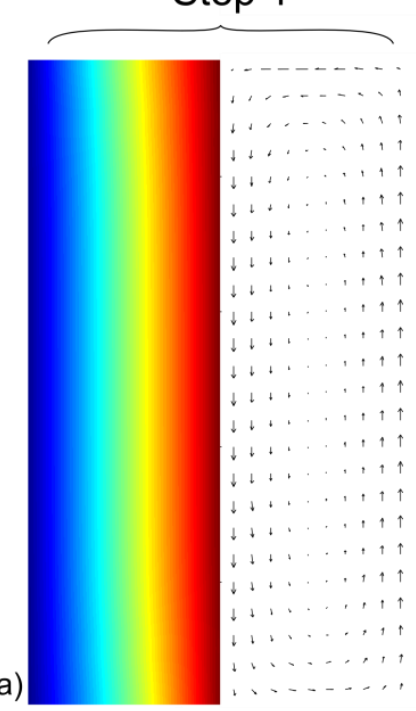

Step 2

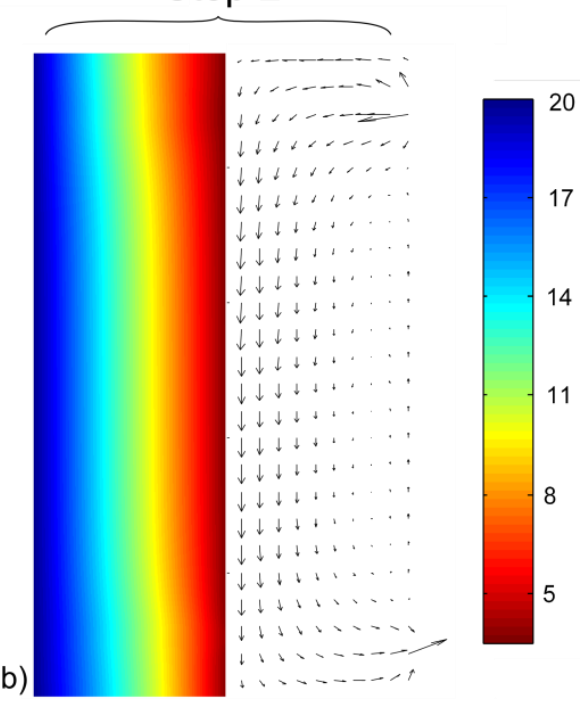

Fig. 8. Simulated temperature $\left({ }^{\circ} \mathrm{C}\right)$ and air velocity field in the insulation layer of FIBREBOARD 1: (a) first measuring step, (b) second measuring step with gaps in interior sheathing (maximum velocity: (a) $0.12 \mathrm{~mm} / \mathrm{s}$ and (b) $15 \mathrm{~mm} / \mathrm{s}$ )

\subsection{Hygrothermal comparison}

With the same notation as explained in section 4.1 the dimensionless vapour pressure profiles across the test walls are presented in Figure $9\left(\mathrm{p}_{\mathrm{v}, \mathrm{in}}=\right.$ vapour pressure in hotbox, $\mathrm{p}_{\mathrm{v}, \mathrm{ex}}=$ vapour pressure in coldbox and $\mathrm{p}_{\mathrm{v}, \mathrm{i}}=$ vapour pressure profile in wall). Vapour pressures are derived from the measured temperatures and relative humidity levels according to:

$$
P_{v}=\phi \cdot \exp \left(65.8-\frac{7066.3}{T}-5.98 \cdot \ln (T)\right)
$$

where $P_{v}(\mathrm{~Pa})$ corresponds to the vapour pressure, $\phi$ to the relative humidity $(\%)$ and $\mathrm{T}(\mathrm{K})$ to the temperature. During the first step the measured data for all four walls shows a similar vapour pressure profile: steep drop behind the vapour retarder (OSB) followed by a slight decrease towards the outer side. Also the simulated profiles follow the same curve. Only for FIBREBOARD 1 the measured vapour pressure at the warm top row is somewhat deviating from the simulated profile. At this row the vapour pressure is slightly higher than the simulated values. This can not be the result of air exfiltration since this should be noticed in the temperature distribution as well. A local decrease of the vapour resistance of the OSB might be a plausible explanation for this (small) discrepancy. 


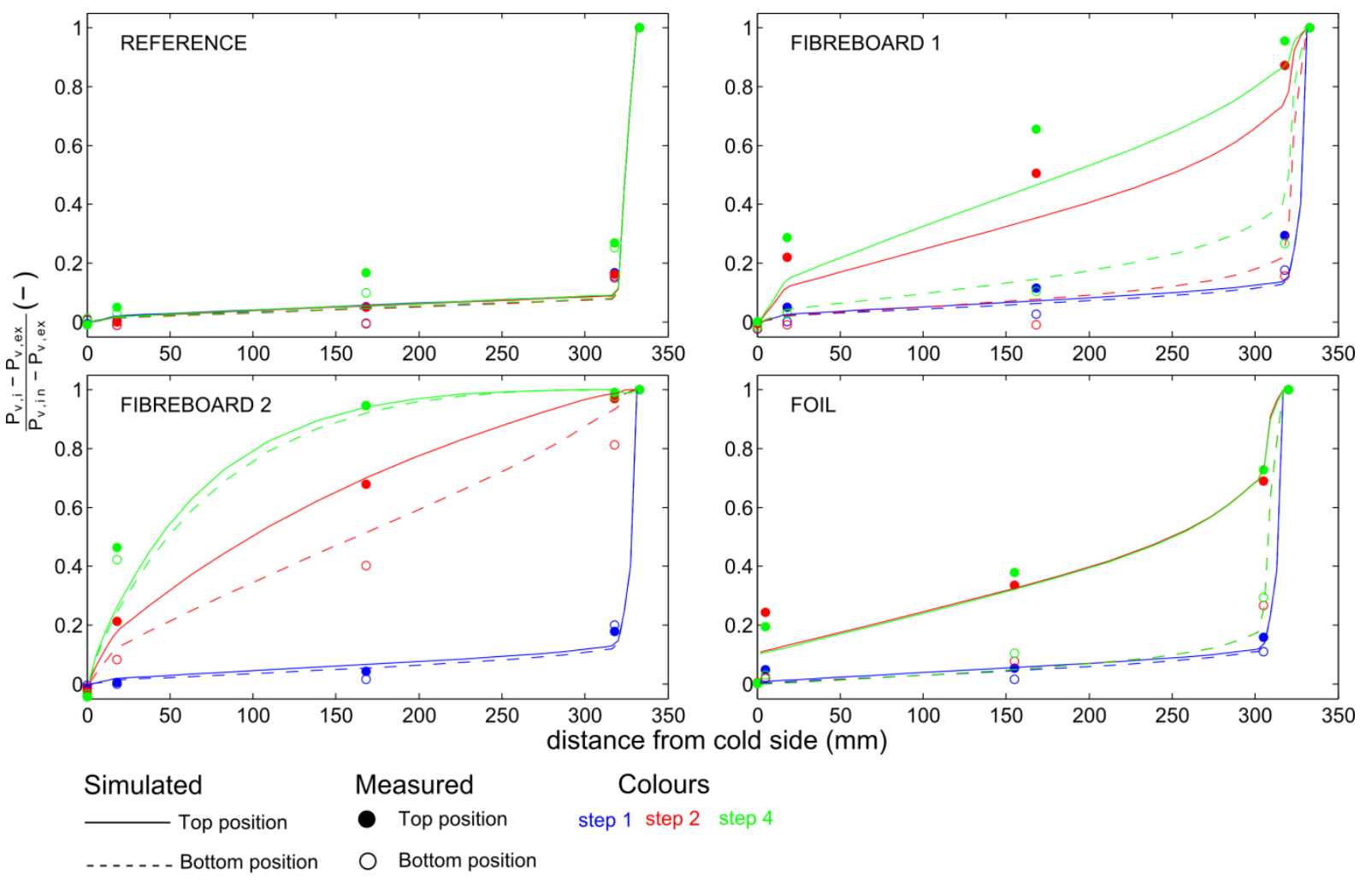

Fig. 9. Simulated vapour pressure distribution at top and bottom position versus measured vapour pressure (via measured relative humidity and temperature) (For interpretation of the references to colour in this figure legend, the reader is referred to the web version of this article.)

In the subsequent step, when the gaps in the interior sheathing are opened, the influence of natural convection on the moisture load becomes very pronounced. The measurements indicate that for all walls with interior gaps the vapour pressure at the top row increases while the vapour pressure at the bottom row remains the same. Only for FIBREBOARD 2 also the vapour pressure at the bottom row increases since forced exfiltration is than already dominant as discussed in section 4.1. The simulations follow the same trends, and thus, confirm the measured values. However, it is noticed that for FIBREBOARD 1 and FOIL the simulated vapour pressure is underestimated by the simulations during this step at the upper cold side.

When an overpressure is realised in the next the vapour pressure profiles support the observations regarding air convection of section 4.1. For FIBREBOARD 1 a slight increase in vapour pressure is noticed as a result of forced exfiltration while this effect is much stronger for the more air permeable wall section FIBREBOARD 2. For the wall with the exterior foil this influence is hardly noticed. Again the simulations show the same observations. On the other hand, differences between the measured and simulated vapour pressure at the cold side still exists. During this step, also the simulated vapour pressure at this position in FIBREBOARD 2 starts to deviate from the measured values. 
Figure 10 visualises the simulated relative humidity field before and after the gaps are created (step 1 and 2) for FIBREBOARD 1. The plot corresponds to the situation at the end of both steps (day 34 and day 61 respectively). The figure shows how after creating top and bottom gaps the relative humidity increases at the upper cold part of the insulation. Combined with the fact that this region also becomes warmer (Figure 8), it can be concluded that this situation is more critical when it comes to mould growth risks.

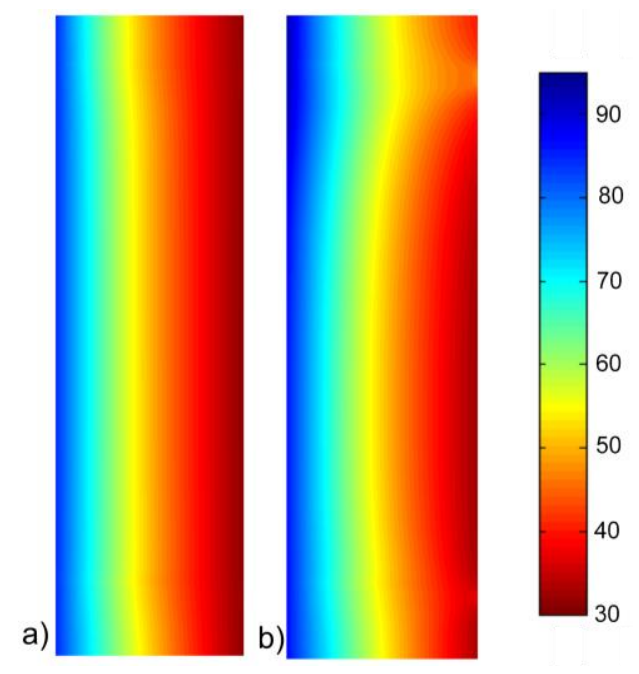

Fig. 10. Simulated relative humidity $(\%)$ in the insulation layer of FIBREBOARD 1: (a) at the end of step 1, (b) at the end of step 2

Figure 11 compares the simulated moisture content of the exterior fibreboard sheathing with the measured weight of the removable specimens in this layer. Here, the measured weights are represented as filled markers and the simulated values are shown as continuous lines as explained in the associated legend. In addition also the effect of a $1 \%$ uncertainty on the sorption isotherm is included in this figure (light-coloured surface) as will be explained later in section 5. The top, mid and bottom height corresponds to black, red and blue respectively.

The measured moisture content of the REFERENCE section (Figure 11a) reaches an almost constant value around $0.1 \mathrm{~kg} / \mathrm{kg}$ at the three heights after a period of hygroscopic loading during the first step. This value drops down to $0.07 \mathrm{~kg} / \mathrm{kg}$ when the drying conditions begin in step 5 . The same trend is predicted by the numerical simulations. The moisture contents are only slightly overestimated by the simulations during the first four steps.

The moisture content evolution at the mid and bottom heights of FIBREBOARD 1 (Figure 11b) are exactly the same as these of the REFERENCE wall. In contrast, from the moment gaps are introduced, the measured moisture content at the top position starts to increase up to $0.18 \mathrm{~kg} / \mathrm{kg}$ at the end of step 4 . The simulations follow the same trend. However, the moisture content at the top row is now slightly underestimated. 


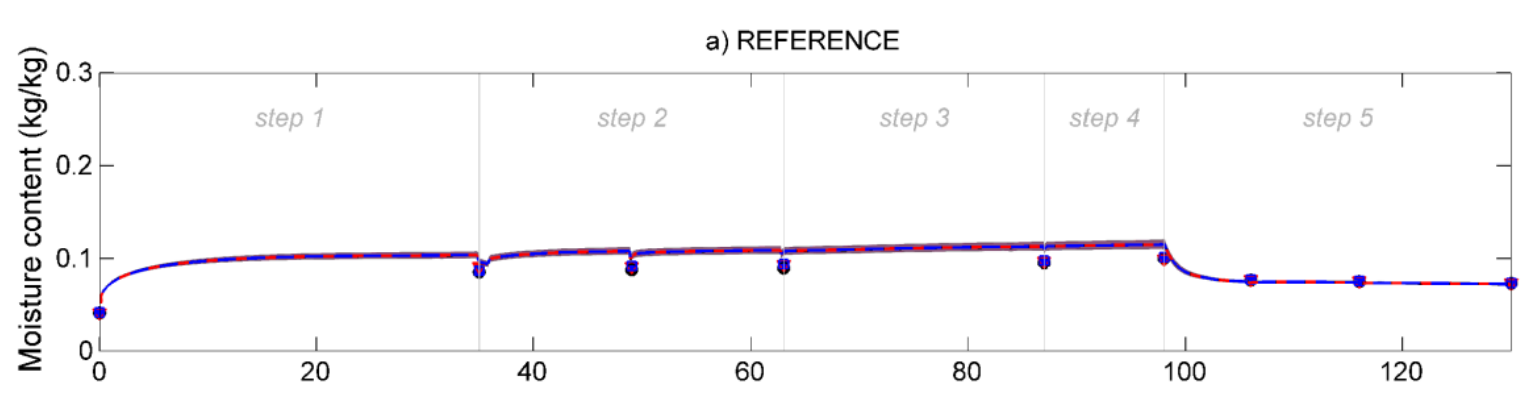

b) FIBREBOARD 1

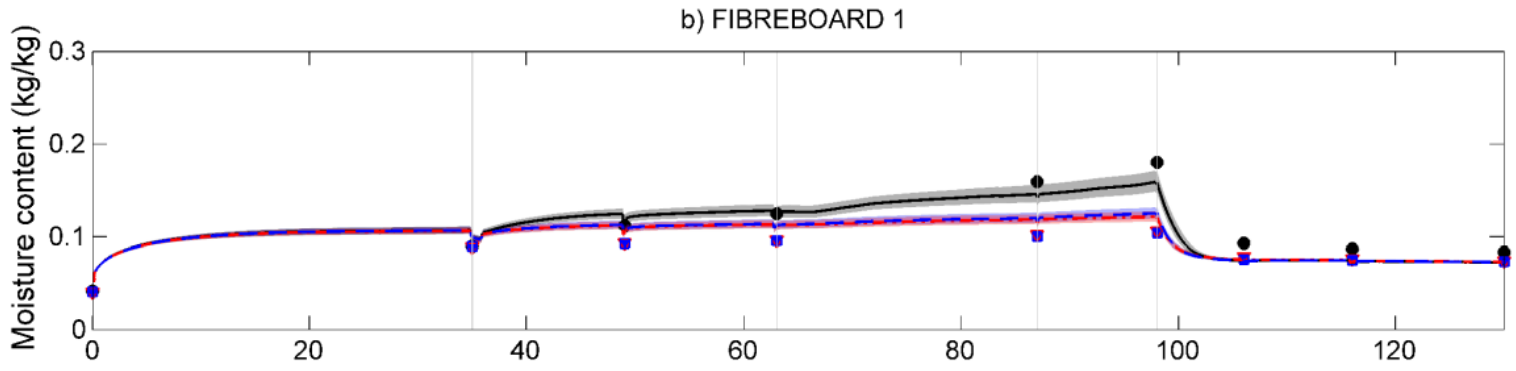

c) FIBREBOARD 2

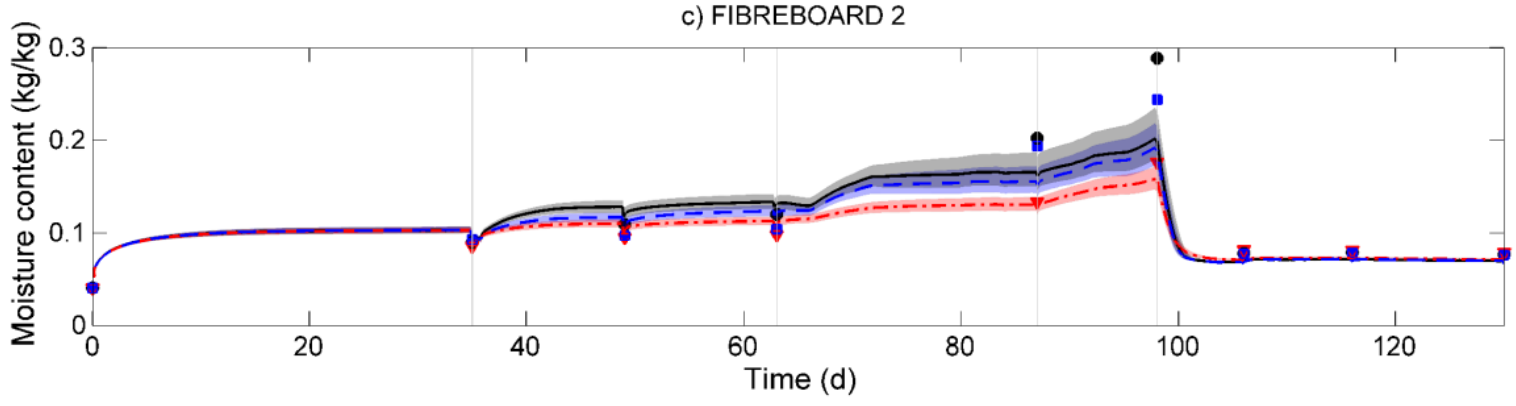

$$
\begin{array}{lll}
\text { Measured } & \text { Simulated } & \pm 1 \% \text { uncertainty on sorption isotherm } \\
\text { - Top height } & & \text { Top height } \\
\cline { 2 - 3 } \text { M Mid height } & -\cdot-\cdot-\text { Mid height } & \text { Mid height } \\
\text { - Bottom height } & ----- \text { Bottom height } & \text { Bottom height }
\end{array}
$$

Fig. 11. Measured versus simulated moisture content of the exterior air barrier. (For interpretation of the references to colour in this figure legend, the reader is referred to the web version of this article.)

In contrast with the first two test sections, the moisture content profiles of FIBREBOARD 2 (Figure 11c) are affected by convection at all three heights. As mentioned in Table 2 its exterior sheathing is twenty times more air open. Consequently, this test wall is more vulnerable towards forced convection once gaps in the interior OSB sheathing are created. Figure 11c shows that both the measured and simulated upper and bottom moisture contents simultaneously increase when a pressure differential of $5 \mathrm{~Pa}$ is applied in step 3 . When the pressure is doubled in step 4 the moisture evolution increases proportionally, reaching a maximum of $0.29 \mathrm{~kg} / \mathrm{kg}$ at the end of this step. The moisture content at the mid height also increases but to a smaller degree. This indicates that the main airflow paths through this wall are short, concentrated at the height of the gaps in the OSB. The figure shows a good agreement between the simulated and measured moisture content at the mid height. However, the higher moisture contents at the upper and bottom row are underestimated at the end of step 4 by $30 \%$ and $20 \%$ 
respectively. When drying conditions are applied in the final step the exterior sheathing dries out rapidly as a result of its high vapour permeability.

\section{Discussion}

In a first step the simulated and measured temperature fields are compared. Both the simulations and measurements show the same temperature profiles for the five measuring stages. However, quantitatively, small discrepancies between the results are noticed. The temperature differences between the top and bottom position at the middle of the insulation are underestimated by the simulations for REFERENCE and FIBREBOARD 1. For example, during the fourth measuring step the difference between the simulated and measured temperature in the middle of the insulation layer at the top row is almost $10 \%$. The origin of these discrepancies are most probably inevitable (small) gaps between the mineral wool and the sheathing materials, which locally decreases the airflow resistance, and thus, increase the effect of natural convection (Janssen, 1997 and Langmans, 2011). To illustrate this impact with a theoretical example, the simulation of FIBERBOARD 1 is repeated including a vertical air channel of $2 \mathrm{~mm}$ along the interface between the insulation and the exterior air barrier. Of course it is unrealistic to assume that a perfect air channel of $2 \mathrm{~mm}$ was left along the vertical sides of the insulation layer. However, the aim of this academic example is to verify the potential impact of small deficiencies related to the installation of the mineral wall blankets. Notwithstanding, mineral wool has a certain resiliency, it is very likely that no perfect contact between the mineral wool insulation and the adjacent layers is obtained for the high insulation thicknesses of this instance.

The air channels are approximated in the model as fully developed laminar flow between two parallel plates based on Janssens' (1998) 2DHAV model. Figure 12 compares the influence of introducing such a small air gap on the simulated temperature profile. The figure illustrates that natural convection in the insulation layer increases by the introduction of this gap, resulting in a higher temperature at the upper cold side on the insulation. As a result the difference between measured and simulated temperatures becomes lower than $3 \%$ for all positions as depicted in figure 12 . 

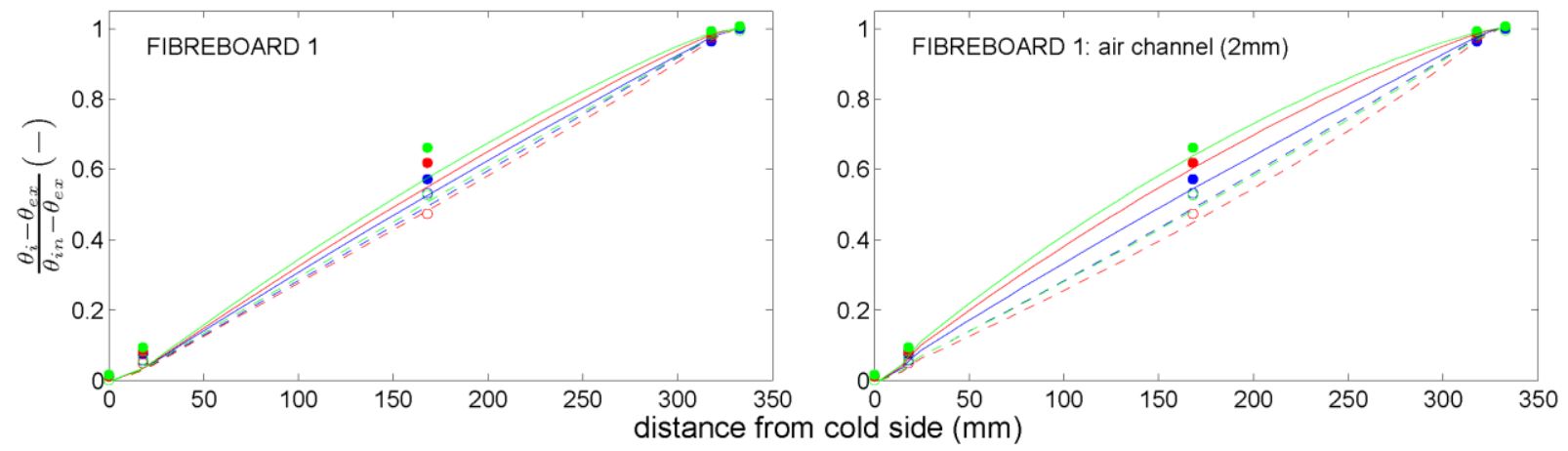

Fig. 12. Comparison between simulated temperature profile in FIBREBOARD 1 (a) with and (b) without are gap of $2 \mathrm{~mm}$ along the interface of the insulation and the exterior air barrier. (For interpretation of the references to colour in this figure legend, the reader is referred to the web version of this article.)

In addition also the impact of an air gap on the simulated vapour pressure profile of FIBREBOARD 1 is given in Figure 13. This figure shows how the maximum deviation reduces from $17 \%$ to $9 \%$ by modelling an air channel along the insulation layer.
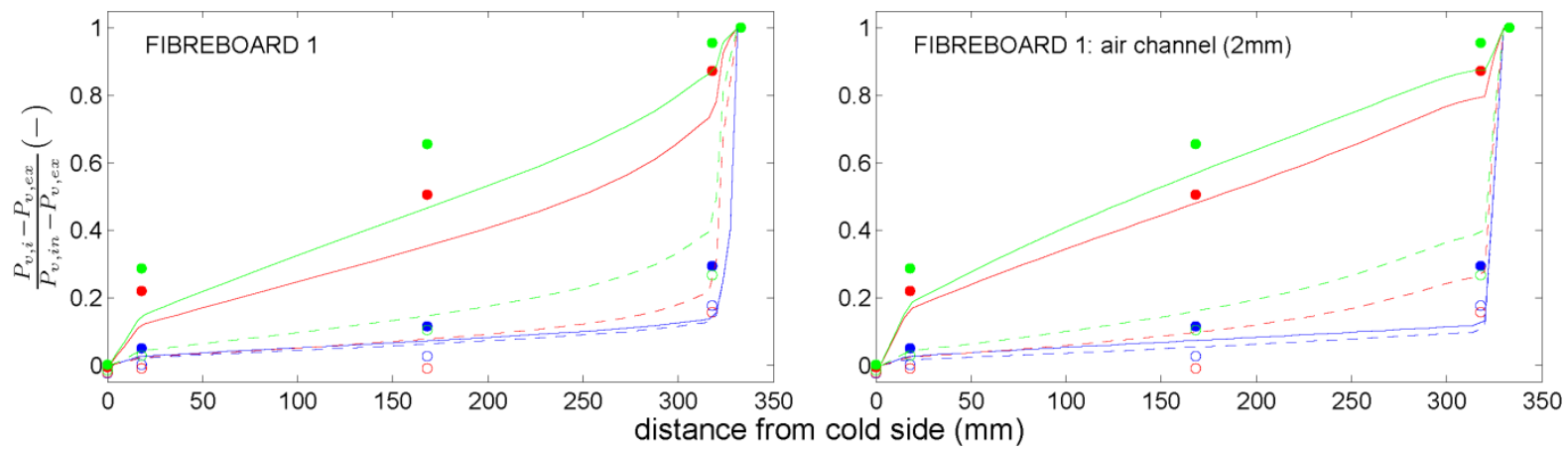

Fig. 13. Comparison between simulated vapour pressure profile in FIBREBOARD 1 (a) with and (b) without are gap of $2 \mathrm{~mm}$ along the interface of the insulation and the exterior air barrier. (For interpretation of the references to colour in this figure legend, the reader is referred to the web version of this article.)

Next, we take a closer look to the simulated and measured evolution of the weight specimens. Again, Figure 10 clearly illustrates the importance of taking buoyancy forces into account (second term in Eq. 7). As a result of natural convection the moisture content at the top row of FIBREBOARD 1 increases, which is nicely captured by the simulations. However, overall it can be concluded that the moisture content levels are underestimated by the simulation in the high relative humidity regime. Most probably, this can be ascribed to uncertainties in the sorption isotherm. The sorption isotherm is commonly determined based on the moisture equilibrium of specimens exposed to relative humidity conditions created by saturated salt solutions in closed desiccators. For this study seven different salts were used with equilibrium relative humidity ranging from $12 \%$ to $97 \%$ (Figure 4a). It is difficult to estimate the possible error on these relative humidity levels. However, to illustrate the 
impact on the simulations we assume an uncertainty of $1 \%$. Figure 14 illustrates the sensitivity of the sorption isotherm for the proposed uncertainty of $1 \%$ on Fibreboard 1.

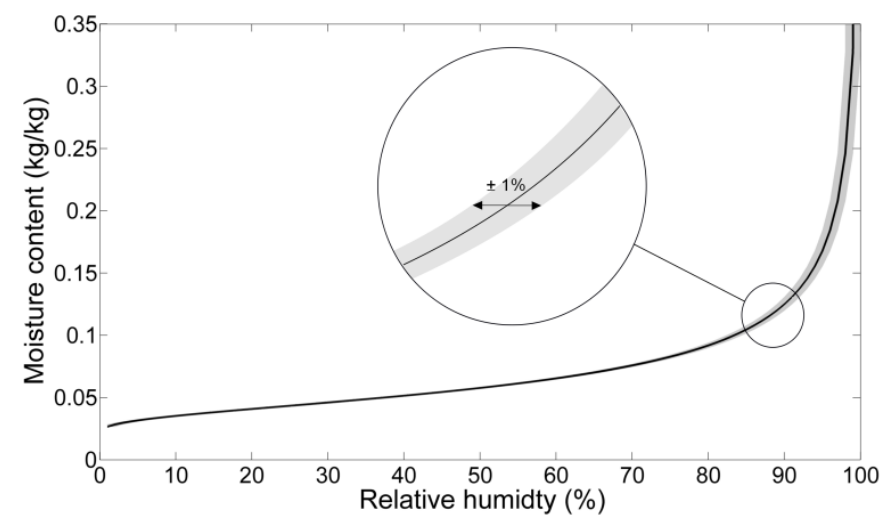

Fig. 14. Effect of a $1 \%$ uncertainty on the sorption isotherm of Fibreboard 1

This figure clearly shows that in the higher relative humidity regime the uncertainly on the moisture content becomes very pronounced. The effects of this uncertainty on the simulation results are included as light-coloured surfaces in Figure 11. As can be seen a small uncertainty in sorption isotherm $( \pm 1 \%)$ has a large impact on the moisture content prediction. In Figure 10c the uncertainty of the moisture content at the top row almost reaches $15 \%$ at the end of step 4.

Finally, the impact of uncertainties in the vapour permeability of the exterior sheathing material are investigated. As mentioned in the discussion of Figure 9, the vapour pressure at the upper cold side was underestimated by the simulations. This was most significant for the wall with an exterior foil (FOIL). This can not be ascribed to an increased amount of natural convection induced by air channels, as for this wall close contact between the foil and the mineral wool could be physically checked. In addition, this is confirmed by the temperature profiles in Figure 8 which are in good agreement with the measured profiles. Thus, as both the mineral wool and the foil have no moisture buffer capacity, these discrepancies are most likely related to an overestimation of the vapour permeability of the foil. To verify this, the simulation of this wall was repeated assuming a constant $\mu \mathrm{d}$ of $0.1 \mathrm{~m}$ for the foil which is the lower accuracy limit defined in ISO:12572. Figure 15 compares the resulting dimensionless vapour pressure profiles with the situation in which the vapour permeance of the foil is simulated according to Figure $5 b$. 

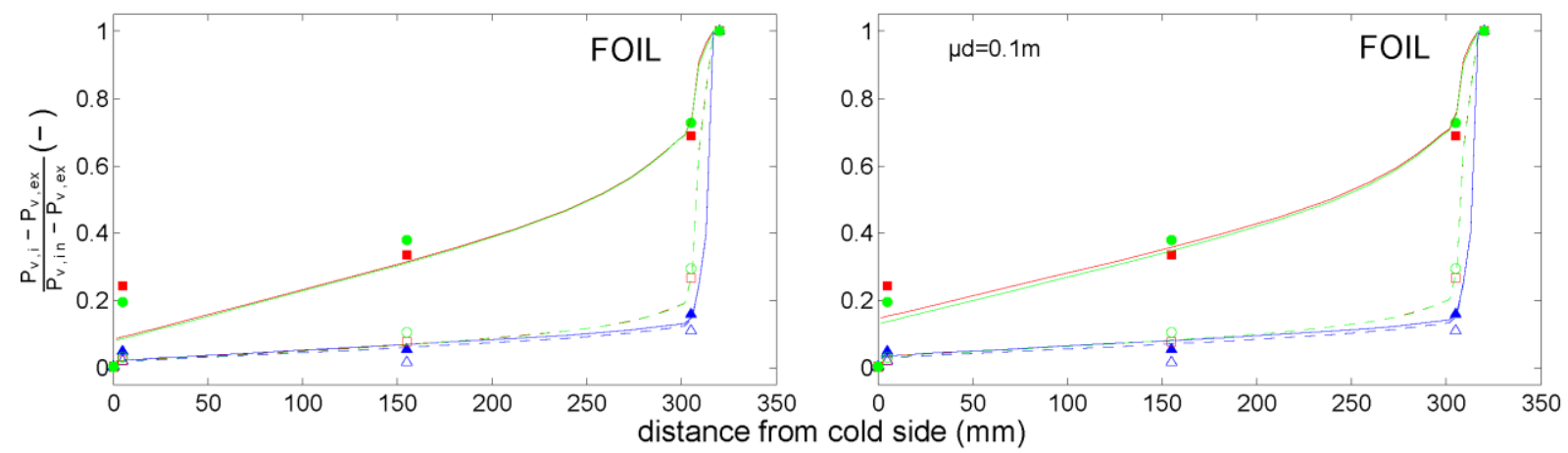

Fig. 15. Comparison between simulated vapour pressure profile in FOIL (a) with the vapour permeability of the foil according to Figure $5 \mathrm{~b}$ and (b) limited to $0.1 \mathrm{~m}$. (For interpretation of the references to colour in this figure legend, the reader is referred to the web version of this article.)

The figure reveals that limiting the $\mu \mathrm{d}$-value of the foil to a constant value of $0.1 \mathrm{~m}$ results in higher vapour pressures at the upper cold side of the insulation, which is in better agreement with the measurements.

This is investigated more in detail in Figure 16 by comparing the relative humidity at this position for both simulations with the measured data. Here, a steep rise of the measured relative humidity is noticed from the second step, reaching almost immediately condensation conditions. Given the error of $\pm 2 \%$ on the applied relative humidity sensors (see Langmans 2012a) this trend is most closely followed by the simulation in which the $\mu \mathrm{d}$-value of the foil is assumed constant $(0.1 \mathrm{~m})$. For the simulation in which the $\mu \mathrm{d}$ of the foil is modelled according to Figure $5 \mathrm{~b}$, however, significant lower relative humidity levels are predicted without reaching condensation conditions. As a consequence, this example demonstrates the necessity to be careful in simulating very vapour open materials as this might result in too optimistic results.

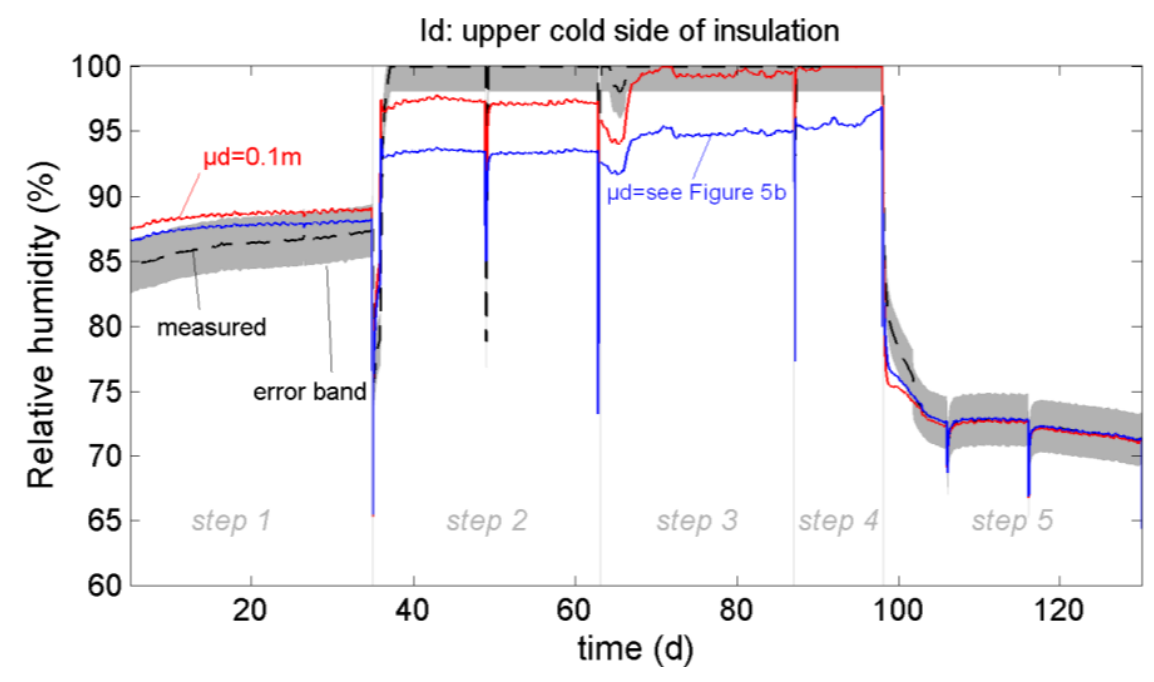

Fig. 16. Comparison of measured relative humidity at upper cold side of the insulation (dashed black line) and the simulation results varying the $\mu$ dimplantation of the foil. 


\section{Conclusions}

The current paper discussed the evaluation of a numerical HAM-model. Simulations were compared with a comprehensive dataset, obtained in studying the hygrothermal impact of highly insulated timber frame walls with an exterior air barrier in laboratory conditions (Langmans, 2012a). The main emphasis of the model evaluation is on the prediction of moisture redistribution driven by natural convection in light insulation material such as mineral wool. The paper focuses on the prediction of moisture, entering the building enclosure through discontinuities in the interior vapour retarder.

A good agreement was found between the measured and simulated data. The results show that including buoyant driven air transport is essential in assessing the hygrothermal response of light weight walls with an exterior air barrier. In this context the model evaluation reveals the importance of considering small imperfections around the insulation layer, resulting in a local increase of the air permeability, and thus, increased effects of natural convection. This was addressed in the paper by extending the porous domain with a hydraulic network to model unintended air channels. Furthermore, the paper shows that accurate material data in the high relative humidity region is essential in predicting the moisture content of the exterior sheathing. Both the impact of (small) imperfections around the insulation layer and uncertainties of the material properties are considered in the comparison of simulation model with the measured data. Overall it can be stated from this analysis that one of the key elements for improving the reliability of today's hygrothermal numerical simulations lies in increasing the accuracy of material properties.

Although this paper focuses mainly on the validation of a numerical model, it stresses the hygrothermal risk of applying exterior air barriers in timber frame construction in cold and moderate climates (no sub-zero temperatures were considered). Both the measured and calculated data reveals that exterior air barriers result in increased moisture loads induced by natural convection. The simulations indicate that even very small air channels along the mineral wool insulation may significantly increase the hygrothermal risk. Further investigations considering other insulation materials, such as blown-in cellulose, or studying the influence of bad workmanship of the insulation layer are required before general recommendations on exterior air barriers can be made.

\section{Acknowledgements}

Research funded by a Ph.D. grant (grant number 81153) of the Institute for the Promotion of Innovation through Science and Technology in Flanders (IWT-Vlaanderen). The authors are grateful to A. Nicolai and J. Grunewald from TUD, for the opportunity to use the open source code of DELPHIN 5. 


\section{References}

Brown, W. C., Bomberg M.T., Ullett J.M. and Rasmussen J. 1993. Measured Thermal Resistance of Frame Walls with Defects in the Installation of Mineral Fibre Insulation. Journal of Building Physics. 16(4):318-339

Derome, D. 2005. Moisture Accumulation in Cellulose Insulation Caused by Air Leakage in Flat Wood Frame Roofs. Journal of Building Physics. 28 (3): 269-287

Grunewald, J.1997. Diffusiver und konvektiver Stoff-und Energietransport. Phd thesis. University of Technology Dresden

Hagentoft, C.E., Kalagasidis A.S., Adl-Zarrabi B., Roels S., Carmeliet J., Hens H., Grunewald J., et al. 2004. Assessment Method of Numerical Prediction Models for Combined Heat, Air and Moisture Transfer in Building Components: Benchmarks for One-dimensional Cases. Journal of Building Physics. 27(4):327-352

Holøs S B and Relander T-O. 2010. Airtightness Measurements of Wood Frame Low Energy, in: Proceedings of $2^{\text {nd }}$ BEST conference. Portland. USA

ISO 8302:1991 'Thermal insulation e Determination of steady- state thermal resistance and related properties Guarded hot plate apparatus'

ISO12572:2001, 'Hygrothermal performance of building materials and products - Determination of water vapour transmission properties'

Janssen, H.. 1997. "Thermal Performance of Highly Insulated Wood Frame Walls.” Master thesis, NTNU

Janssens, A, and H Hens. 2003. Interstitial Condensation Due to Air Leakage: A Sensitivity Analysis. Journal of Building Physics. 27 (1): 15-29.

Janssens, Arnold. 1998. Reliable control of interstitial condensation in lightweight roof systems. K.U.Leuven, Phd dissertation. Laboratorium Bouwfysica. Heverlee.

Jokisalo J., Kurnitski J., Korpi M., Kalamees T. and Vinha J. 2009. Building leakage, infiltration, and energy performance analyses for Finnish detached houses. Building and Environment. 44(2):377-387.

Kalamees, T. 2007. Airtightness and air leakages of new lightweight single-family detached houses in Estonia. Building and Environment. 42(6) 2369-2377.

Kalamees, T. and Vinha J. 2003. Hygrothermal calculations and laboratory tests on timber-framed wall structures. Building and Environment. 38 (5) (May): 689-697.

Kalamees, T. and Kurnitski J. 2009. Moisture Convection Performance of External Walls and Roofs. Journal of Building Physics. 33(3): 1-23.

Kumaran K. (1996) Material properties - Final report, vol. 3. Belgium, KU Leuven: Building physics section, civil engineering

Langmans J., Klein R., De Paepe M., and Roels S. 2010. Potential of wind barriers to assure airtightness of wood-frame low energy constructions. Energy and Buildings. 42(12)

Langmans J, Nicolai, Klein R, Grunewald J, Roels S. 2011. Numerical Simulation of Building Components Towards an Efficient Implementation of Air Convection in HAM-models, In 9th Nordic Symposium on Building Physics, Tampere, Finland: 399-405

Langmans J., Klein R., Roels S. 2012a. Hygrothermal risks of using exterior air barrier systems for highly insulated light weight walls: a laboratory investigation. Building and Environment, 56 (10)

Langmans, J., Nicolai, A., Klein, R., Roels, S. 2012b. A quasi-steady state implementation of air convection in a transient heat and moisture building component model. Building and Environment, 58 (12), 208-218.

Li, Qinru, Jiwu Rao, and Paul Fazio. 2009. "Development of HAM tool for building envelope analysis." Building and Environment 44 (5) (May): 1065-1073.

Nicolai A. 2007. Modelling and numerical simulation of salt transport and phase transitions in unsaturated porous building materials, Phd dissertation, Syracuse University, USA

Relander T.O., Bauwens G., Roels S., Thue J.V., and Uvsløkk S. 2011. The influence of structural floors on the airtightness of wood-frame houses. Energy and Buildings. 43: 639-652.

Riesner, Katrin. 2003. Natürliche konvektion in losen Ausenwanddämmungen. Universität Rockstock.

Roels S, Carmeliet J, Hens H, Adan O, Brocken H, Cerny R, et al. A Comparison of Different Techniques to Quantify Moisture Content Profiles in Porous Building Materials. Journal of Thermal Envelope and Building Science. 2004;27(4):261-276

Sandberg, P. I., Bankvall, C., Sikander, E., Wahlgren, P., and Larsson, B. 2007. The effect and cost impact of poor airtightness - information for developers and clients. Proceedings of Thermal Performance of the Exterior Envelopes of Whole Buildings X International Conference. Clearwater Beach. Florida

Teasdale-St-Hilaire, A. and Derome D. 2007. Comparison of experimental and numerical results of wood-frame wall assemblies wetted by simulated wind-driven rain infiltration. Energy and Buildings. 39 (11)

Tenwolde A. and Rose W.B. 1996. Moisture Control Strategies for the Building Envelope. Journal of Building Physics. 19(3):206-214

Thue, J.V., Skogstad H.B. and Homb A. 1996. Wood Frame Walls in Cold Climate -Vapour Barrier Requirements. Journal of Building Physics. 20 (1) 
Økland, Ø. 1998. Convection in highly-insulated building structures. Phd dissertation Norwegian University of Science and Technology. 